\title{
THIN-WALLED EPOXY-GLASS FIBRE BEAMS SUBJECTED TO PURE BENDING
}

\author{
Tomasz KUBIAK*, Zbigniew KOŁAKOWSKI
}

\author{
*Mechanical Engineering Faculty, Department of Strength of Materials, Lodz University of Technology, ul. Stefanowskiego 1/15, 90-924 Lódź, Poland
}

tomasz.kubiak@p.lodz.pl, zbigniew.kolakowski@p.lodz.pl

\begin{abstract}
Buckling and postbuckling behaviour of thin-walled channel section beam made of epoxy-glass composite have been considered. The beams under analysis was subjected to pure bending. The main aim was check the influence of ply arrangement on buckling load and postbuckling behaviour and validate the authors analytical-numerical method by commercial finite element method software. Mentioned analytical-numerical method has been developed for more than 25 years in Department of Strength of Materials. This method uses asymptotic Koiter theory for conservative systems in the second order approximation modified by Byskov and Hutchinson. Additionally, using the finite element method software the influence of ply arrangement on failure load were checked.
\end{abstract}

Key words: Thin-Walled Structures, Composite Structures, Stability, Postbuckling Behaviour

\section{INTRODUCTION}

The thin-walled structure is a structure which consists of one or several thin plates or shells connected together at their common edges. Among thin-walled structures, plates, girders, beams, columns and shells are included. It is almost impossible to draw precisely the borderline between thin-walled elements and elements with average thickness. In the literature, one can find the information that the thin-walled rod is the one in which the wall thickness is at least 10 times smaller than the smallest crosssectional dimension

Buckling and postbuckling of thin-walled structures subjected to static load have been investigated by many authors for more than one hundred years. The following scientists: Euler (1910), Timoshenko (1961) and Volmir (1967) should be included in the group of precursors of the investigations on stability of the thinwalled structure problem.

In the world wide literature, papers dealing with nonlinear problems of stability of thin-walled structures made of orthotropic materials can be found easily. The oldest work on this subject was published almost 80 years ago. Seydel (1933), Smith (1944) dealt with orthotropic plate buckling. Reissner and Stavsky (1961) published a study on the critical stress for anisotropic laminated plates with arbitrarily stacked layers. The theoretical background for buckling of composite and anisotropic plates was published by Lekhnitskii (1947), Ambartsumyan (1970), Ashton and Whitney (1970) or Vinson and Chon (1975). In the literature, there are many works on anisotropic plates - among them, March's (1942) and Thielmann's (1950) works are worth mentioning. Fraser and Miller (1970) established the critical load for orthotropic plates using the Ritz method. Mandell (1968) presented the results of experimental studies on buckling of anisotropic rectangular plates with simply supported or clamped edges. Chailleux et al. (1975) delivered the results of experimental studies on the stability of columns and square laminate plates. Noor (1975) in his work presented a comparison between the classical theory of plates, the theory of linear shear and a 3-D theory for elastic stability of orthotropic laminated plates. Chandra and Raju (1973) pub- lished a study on the postbuckling behaviour of orthotropic rectangular plates with simply supported edges. They analysed plates subjected to load causing uniform shortening of edges. They compared the results of their study with the previously published works. A similar problem was solved by Prahakara and Chia (1973). They carried out a theoretical analysis of the postbuckling behaviour of orthotropic, rectangular plates with simply supported edges and subjected to biaxial compression. To describe the deformation, a double Fourier series was used. Massey (1971) and Brunelle (1983) looked for areas of instability for orthotropic plates subjected to pure shear. Libove (1983) and Ting with co-authors (1987) analysed the unstable behaviour of orthotropic plates under biaxial load.

The employed analytical-numerical method, developed in Department of Strength of Materials of Lodz University of Technology, was presented in monograph edited by Kołakowski and Kowal-Michalska (1999). In mentioned above monograph the results of calculation for plates and beam-columns made of orthotropic materials can be found. The analysed structures are made of homogeneous orthotropic material. In contrast of that models in this publication layered composites were considered.

The latest work dealing with buckling and postbuckling behaviour of thin-walled columns made of epoxy-carbon composite subjected to compression was published by Dębski, Kubiak and Teter (2013). They compare finite element method, analyticalnumerical method and experimental results. The beam-columns made of composite material subjected to bending can be found in paper written by Kołakowski and Mania (2013), who introduced the semi analytical method for determined the postbuckling behaviour of multilayered composite. The same method was also used in this paper.

Thin-walled structures especially made of composite materials have an ability to form freely the cross-section as well as a ply arrangement and, thus, to maximize strength and load carrying capacity. Therefore, they have been more and more often used in many industries for example they are used in sport and automotive industry and aerospace. As an example of such structural elements, a snowboard, a ski or poles can be mentioned, as well 
as all kinds of crane girders, structural components of automobiles (a car body sheathing and all longitudinal members), aircraft fuselages and wings.

It should be remember that the thin-walled structures exhaust their carrying capacity not by exceeding allowable stresses but by a stability loss. Therefore, not only the critical load but also the postbuckling behaviour provides essential knowledge for designers.

The Authors of this paper decided to adapt previously developed analytical-numerical method to analyse postbuckling behaviour of thin-walled structures made of multilayered fibre composite. As an example of the considerations the multi-layer glass fibre composite channel section beam was taken. It was assumed that the beam is made of eight-ply laminate, where each can have different orientation but finally quasi-isotropic arrangement.

The main goal of the study was choosing a few ply arrangements that will be used in the samples (channel section profiles) to the experimental studies, that in turn will allow to validate the results of calculations.

The epoxy-glass fibre composite have been used as a material of considered thin-walled channel section beams subjected to pure bending. The buckling load and the postbuckling behaviour have been analysed.

\section{METHODS OF SOLUTION}

Two method of solution have been employed. The commercial software ANSYS ${ }^{\circledR}$ based on finite element method and analyticalnumerical method. The results obtained by two mentioned above method was compared.

The finite element method commercial software (ANSYS ${ }^{\circledR}$ ) was employed to validate the results obtained from analyticalnumerical method.

The finite element method have been also used to determine the failure load.

\subsection{Analytical-numerical method}

The analytical-numerical method (Kolakowski and KowalMichalska 1999, 2012, Kubiak 2001) have been employed to analyse the static buckling, post buckling behaviour of thin-walled structures composed of plates made of orthotropic or composite materials.

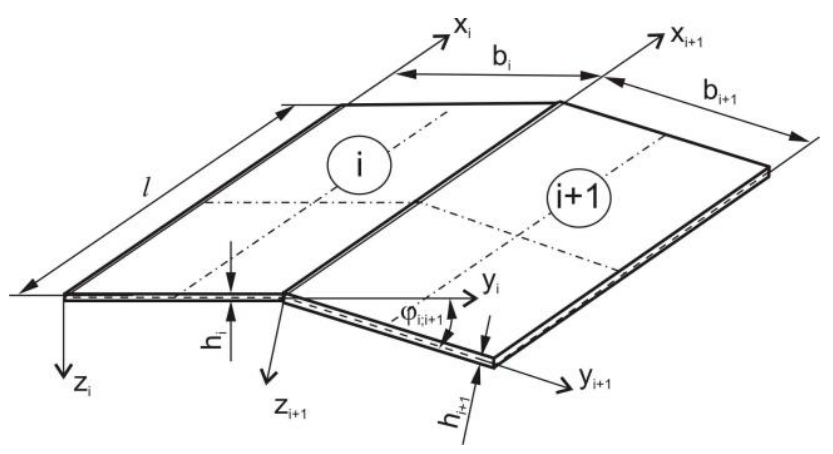

Fig. 1. Geometrical dimensions and local coordinate systems of adjacent plates
In the employed method the beams under analysis are simply supported at loaded ends. The beam's wall are rectangular and can be orthotropic with the principal axes of orthotropy parallel to the plate edges or have a quasi-isotropic ply arrangement. It was assumed that the considered beams are made of a material that governed by Hooks Law. The loaded edges remain straight and parallel during loading. Additionally, it is assumed that normal and shear forces disappear along the unloaded edges.

Thin-walled prismatic columns of a length $l$ composed of rectangular plate segments (Fig. 1) interconnected along longitudinal edges are considered.

For the $i$-th plate component, precise geometrical relationships are assumed in order to enable the consideration of both out-ofplane and in-plane bending of each plate (Kolakowski, KowalMichalska 1999, 2012, Kubiak 2001):

$$
\begin{aligned}
& \varepsilon_{i x}=u_{i, x}+\frac{1}{2}\left(w_{i, x}^{2}+u_{i, x}^{2}+v_{i, x}^{2}\right), \\
& \varepsilon_{i y}=v_{i, y}+\frac{1}{2}\left(w_{i, y}^{2}+u_{i, y}^{2}+v_{i, y}^{2}\right), \\
& 2 \varepsilon_{i x y}=\gamma_{i x y}=u_{i, y}+v_{i, x}+w_{i, x} w_{i, y}+u_{i, x} u_{i, y}+v_{i, x} v_{i, y},
\end{aligned}
$$

where: $u_{i}, v_{i}, w_{i}$ - displacement components of the middle surface of the $i$-th plate in the $x_{i}, y_{i}$, and $z_{i}$ directions, correspondingly.

The differential equilibrium equations (2) have been obtained taking into account Lagrange's description, full Green's strain tensor for thin plates and Kirchhoff's stress tensor.

$$
\begin{aligned}
& N_{x i, x}+N_{x y i, y}+ \\
& +\left(N_{y i} u_{i, y}\right)_{, y}+\left(N_{x i} u_{i, x}\right)_{, x}+\left(N_{x y i} u_{i, x}\right)_{, y}+\left(N_{x y i} u_{i, y}\right)_{, x}=0, \\
& N_{x y i, x}+N_{y i, y}+ \\
& +\left(N_{x i} v_{i, x}\right)_{, x}+\left(N_{y i} v_{i, y}\right)_{, y}+\left(N_{x y i} v_{i, x}\right)_{, y}+\left(N_{x y i} v_{i, y}\right)_{, x}=0, \\
& \left(N_{x i, x}+N_{x y i, y}\right) w_{i, x}+\left(N_{y i, y}+N_{x y i, x}\right) w_{i, y}+N_{x i} w_{i, x x}+ \\
& +N_{y i} w_{i, y y}+2 N_{x y i} w_{i, x y}+M_{x i, x x}+2 M_{x y i, x y}+M_{y i, y y}=0,
\end{aligned}
$$

where $\mathrm{N}$ and $\mathrm{M}$ are sectional forces and moments.

After expanding the fields of displacements $U$ and the fields of sectional forces $\mathbf{N}$ into a power series with respect to the mode amplitudes $\xi$ (the dimensionless amplitude of the buckling mode), Koiter's asymptotic theory has been employed (Koiter, 1976):

$$
\begin{aligned}
& \mathbf{U}_{i}=\lambda \mathbf{U}_{i}^{(0)}+\xi \mathbf{U}_{i}^{(s)}+\xi^{2} \mathbf{U}_{i}^{(s s)}+\ldots . . \\
& \mathbf{N}_{i}=\lambda \mathbf{N}_{i}^{(0)}+\xi \mathbf{N}_{i}^{(s)}+\xi^{2} \mathbf{N}_{i}^{(s s)}+\ldots . .
\end{aligned}
$$

where: $\lambda$ is the load parameter; $\mathbf{U}^{(0)}, \mathbf{N}^{(0)}$ the pre-buckling state fields for $i$-th wall and $\mathbf{U}(\mathrm{s}), \mathbf{N}(\mathrm{s})$ the buckling mode fields, and $\mathbf{U}(\mathrm{ss})$, $\mathbf{N}$ (ss) are the post-buckling fields (the second order approximation) for the $i$-th plate. The non-linear problem was solved with the Byskov and Huchinson (1977) asymptotic theory application. By substituting displacements obtained from assumed expansion of the fields of displacements (3) into equations of equilibrium (2), the junction conditions and the boundary conditions, the boundary problems of zero, first and second order could be obtained. The first and second order approximations in the middle plate plane have been solved with a modified transition matrix method. The state vector at the final edge based on the state vector at the initial edge has been found by a numerical integration of differential equations (2) along the transverse direction using the RungeKutta formulae by means of the Godunov orthogonalization method. The above-mentioned method allows for finding the nonlinear 
postbuckling coefficients $a_{\text {sss }}$ and $b_{\text {ssss }}$ applied in the equation describing the postbuckling equilibrium path (Kubiak 2001):

$$
\left(1-\frac{\lambda}{\lambda_{s}}\right) \xi+a_{s s s} \xi^{2}+b_{s s s s} \xi^{3}+\ldots=\xi^{*} \frac{\lambda}{\lambda_{s}} ;
$$

where: $\lambda_{s}$ is the critical load corresponding to the $s$-th mode and coefficient $a_{\text {sss, }}, b_{\text {ssss }}$ are:

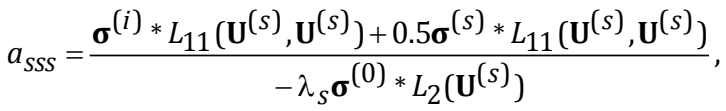

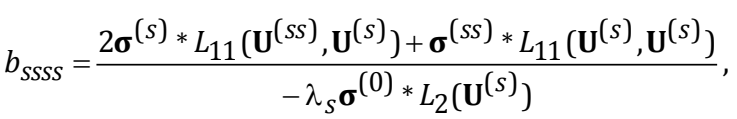

where: $L_{11}$ is a bilinear operator, $L_{2}$ is a quadratic operator, and $\sigma(s), \sigma^{(s s)}$ are stress field tensors in the first and second order.

The postbuckling static equilibrium paths (4) for the lowest $(s=1)$ uncoupled buckling load $\lambda_{s}=\lambda_{c r}$ has the form:

$$
\left(1-\frac{\lambda}{\lambda_{c r}}\right) \xi+a_{111} \xi^{2}+b_{1111} \xi^{3}=\xi^{*} \frac{\lambda}{\lambda_{c r}}
$$

Till now in developed analytical-numerical method the second order approximation for multilayer composite plate or beams wall is not included. However, Kolakowski proposed the semi analytical method allowing to find coefficient $b_{1111}$, which according to (Kołakowski and Kowal-Michalska, 2012; Kołakowski and Mania 2013) is:

$$
b_{1111} \approx \boldsymbol{\sigma}^{(11)} L_{2}\left(\mathbf{U}^{(1)}\right)+\frac{\lambda_{c r} \boldsymbol{\sigma}^{(0)} L_{2}\left(\mathbf{U}^{(1)}\right)}{2 \boldsymbol{\sigma}^{(0)} \boldsymbol{\varepsilon}^{(0)}} .
$$

\subsection{Finite element method}

The ANSYS ${ }^{\circledR}$ software based on finite element method was used to perform nonlinear buckling analysis and determine the postbuckling behaviour of channel sections beams subjected to pure bending.

To solve the nonlinear problem the iterative Newton-Raphson method is employed.

In numerical (FEM) model the four-node shell element with six degrees of freedom at each node have been taken to discretisation the considered channel section beam. The number of elements has been assumed on the basis of experience (e.g. Kolakowski and Kubiak, 2005) - the mesh density has been assumed in such a way as not to limit the deformation of the beam.

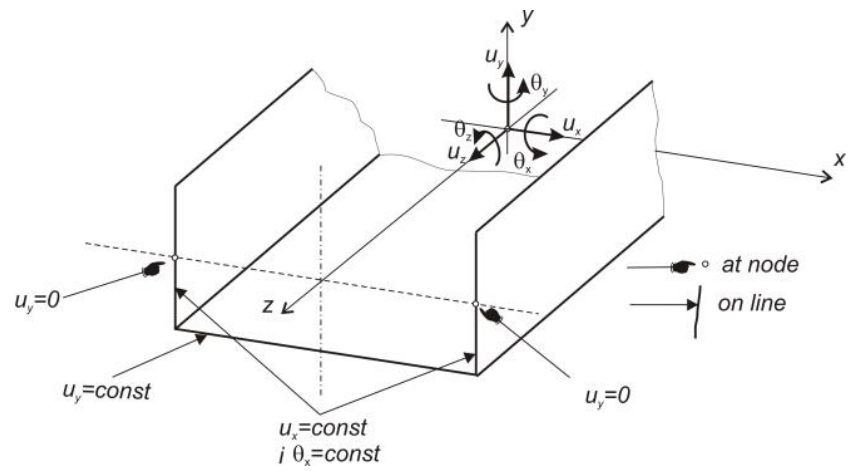

Fig. 2. Assumed boundary conditions

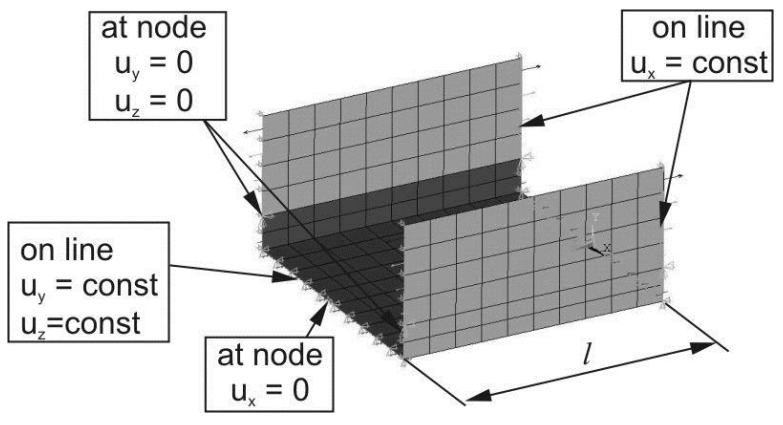

Fig. 3. Assumed boundary conditions

The assumed boundary conditions are presented in Figs. 2 and 3 .

It was assumed that bending (the flexural buckling mode) occurred around the axis for which the second moment of area is the smallest, thus the FEM model was prepared in such a way that nodes in which the displacement in the $y$ direction was set to zero were on the neutral axis of ending sections. Straightness of the loaded edges of the considered beam-column is provided by requiring equal displacements of all nodes lying on the edge of the beam-column in the direction normal to its walls. To ensure that deformations are compatible with the deflection in bending (the global flexural buckling mode), the edges normal to the neutral axis remained straight in the plane containing the wall of the column. In addition, for all nodes lying on those edges, the constant rotation around the axis parallel to the axis of the neutral section was presupposed.

The bending load was applied as a stress distribution, which was modelled in the form of the pressure distribution acting along the loaded edges of the structure (Fig. 4).

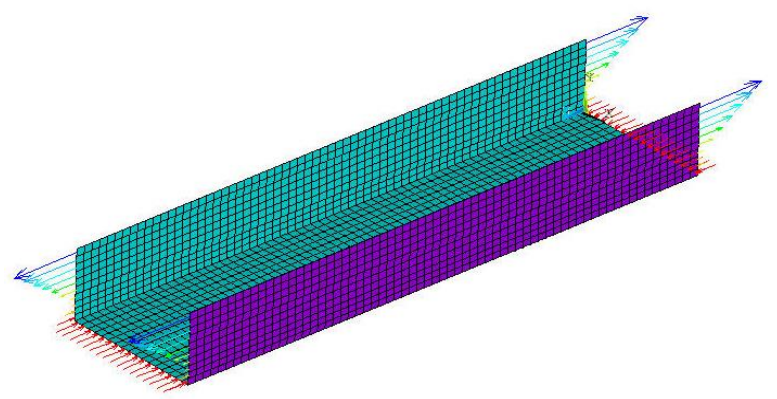

Fig. 4. Assumed FEM model of load

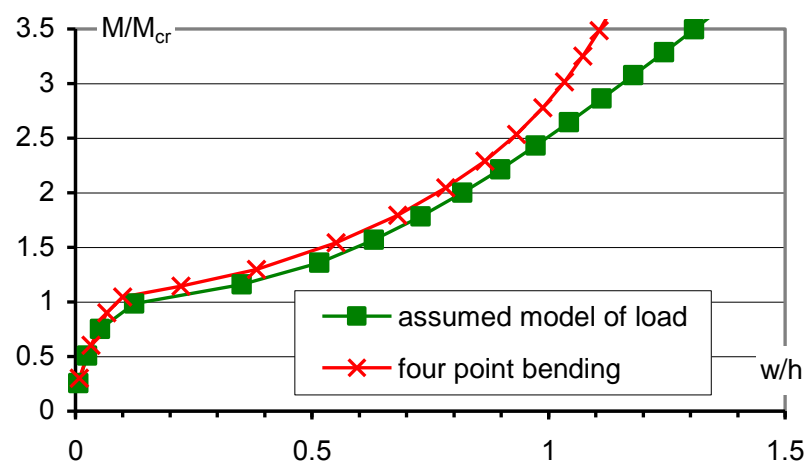

Fig. 5. Postbuckling equilibrium path for the channel section $50 \times 25 \times 1$ beam of the length $l=200 \mathrm{~mm}$ 
It should be noted that the assumed load is non-conservative - pressure is always perpendicular to the area to which it is applied - but for load which are less then two times the buckling load the differences in results can be neglected (Fig. 5).

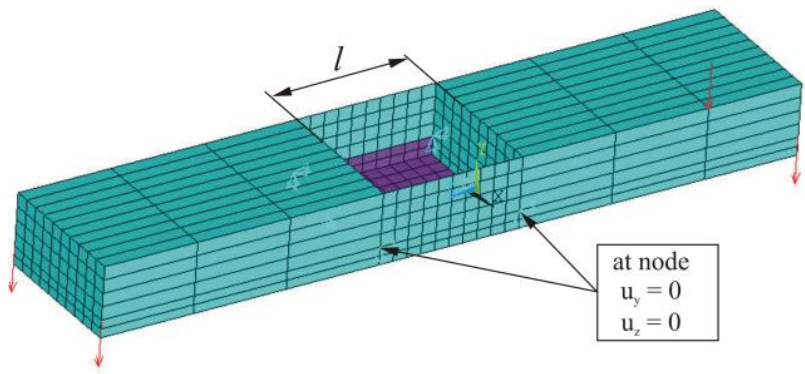

Fig. 6. FEM model for four point bending

The assumed FEM model for four point bending test is presented in Fig. 6.

\section{RESULTS OF CALCULATIONS}

The calculations have been performed using FEM and analytical-numerical method (ANM). The channel section composite beam (Fig. 7) with different ply arrangement and length $l=80$ $\mathrm{mm}$ was considered. The following ply arrangement was taken into account:

- C1: [0/-45/45/90]s;

- C2: $[90 /-45 / 45 / 0] \mathrm{s} ;$

- C3: $[90 / 0 / 90 / 0] \mathrm{s} ;$

- C4: [0/90/0/90]s;

- C5: $[45 /-45 / 45 /-45] s ;$

- C6: $[45 /-45 / 45 / 0] \mathrm{s} ;$

- C7: $[45 /-45 / 90 / 0] s$.

The initial geometrical imperfection amplitude equals 0.01 of wall thickness was assumed.
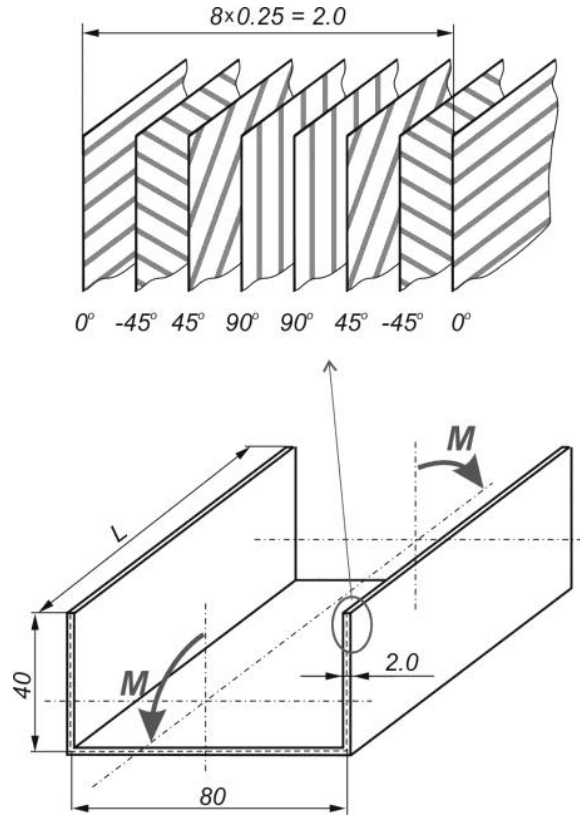

Fig. 7. Load, dimension and exemplary ply arrangement of considered channel section beam
The ply arrangement influence on buckling load and postbuckling behaviour have been analysed. The buckling loads comparison are presented in Tab. 1. The lengths $L_{c r}$ of beams for which the lowest critical moment corresponding to local buckling and one half-wave in longitudinal direction have been calculated are also listed in Tab. 1. The buckling load obtained by two employed method are in very good agreement.

Tab. 1. Buckling load $M_{\mathrm{cr}}$ and critical length $L_{\mathrm{cr}}$ corresponding to local buckling mode

\begin{tabular}{|l|c|c|c|}
\hline \multicolumn{1}{|c|}{ ply arrangements } & ANM & FEM & $\begin{array}{c}\text { length of one } \\
\text { half-wave } \\
L_{\text {cr }}[\mathrm{mm}]\end{array}$ \\
\hline C1: $[0 /-45 / 45 / 90] \mathrm{s}$ & 6.2 & 6.2 & 80 \\
\hline C2: [90/-45/45/0]s & 6.3 & 6.2 & 52 \\
\hline C3: [90/0/90/0]s & 6.2 & 6.2 & 67 \\
\hline C4: [0/90/0/90]s & 6.1 & 6.1 & 71 \\
\hline C5: $[45 /-45 / 45 /-45] s$ & 6.9 & 7.2 & 63 \\
\hline C6: $[45 /-45 / 45 / 0] s$ & 6.9 & 7.1 & 63 \\
\hline C7: $[45 /-45 / 90 / 0] s$ & 6.9 & 7.2 & 60 \\
\hline
\end{tabular}

The postbuckling equilibrium paths obtained with analyticalnumerical method are shown in Fig. 8. There are three groups of ply arrangements (1st: C2 and C3; 2nd: C4, C6 and C7; 3rd: C1 and C5) and in each of these the course of equilibrium paths are similar. Taking above into account further calculation was made for ply arrangement denoted as C1, C2 and C4.

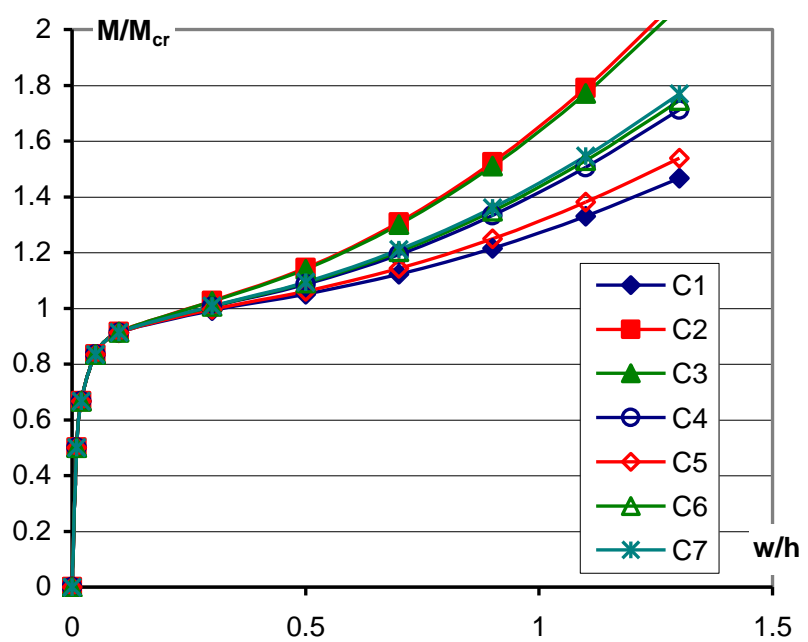

Fig. 8. Postbuckling equilibrium paths for channel section beam with different ply arrangement

The comparison of courses of postbuckling equilibrium paths for different ply arrangement denoted by $\mathrm{C} 1, \mathrm{C} 2$ and $\mathrm{C} 4$ obtained with FEM and ANM for beams of length $L=80 \mathrm{~mm}$ are presented in Fig. 9. The differences in dimensionless load $M / M_{c r}$ for given dimensionless deflection $\mathrm{w} / \mathrm{h}=1$ reach as much as $20 \%$ for beams with ply arrangement C2. These differences growing with increasing dimensionless deflection w/h. Taking above into account and knowing that the Koiter approach does not take into account stiffening the structure associated with the fact that part of the section is tensed it was decide to check the influence of ten- 
sile stress on beam stiffness - checking the change of course of postbuckling paths. The differences depending on approach are presented in Fig. 10.

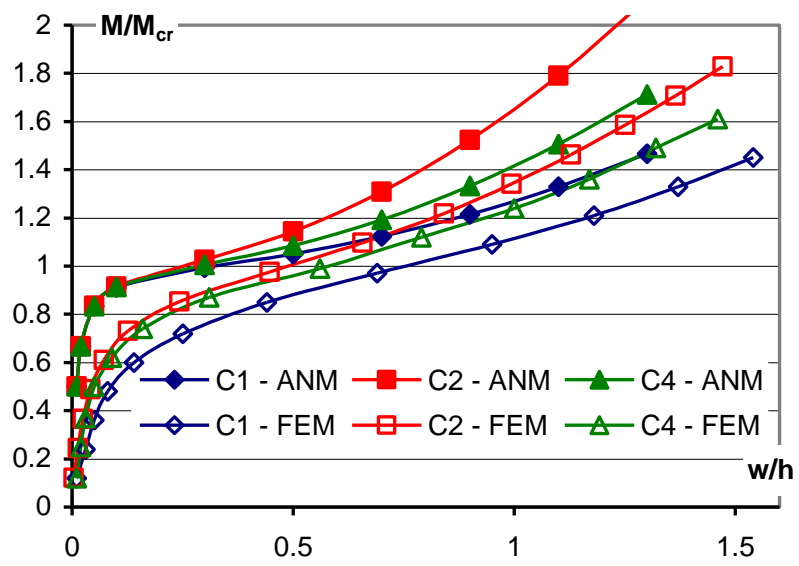

Fig. 9. FEM and ANM results comparison for channel section beam with different ply arrangement

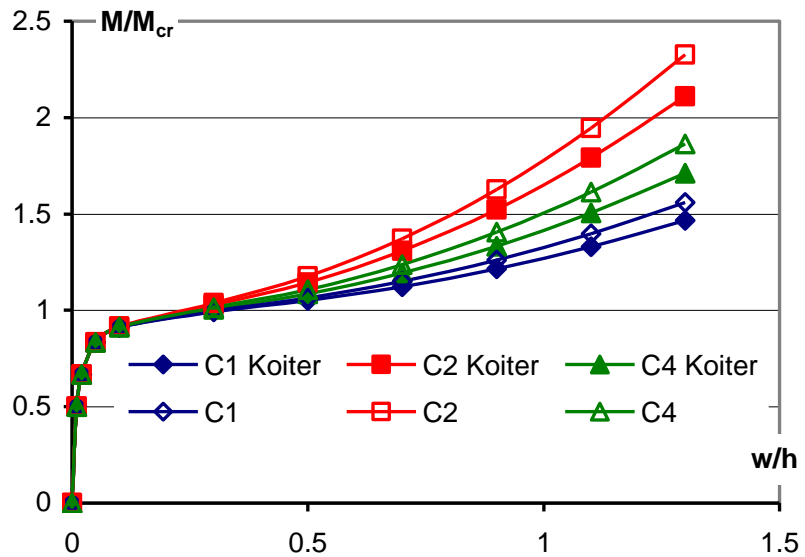

Fig. 10. Postbuckling equilibrium paths obtained with Koiter or authors approach

Taking into account the stiffening beams caused by sectional tension forces the differences between results obtained with analytical-numerical method and finite element method are greater than presented in Fig. 9 - the results comparison for beam of length $L=150 \mathrm{~mm}$ with layers arrangement $\mathrm{C} 2$ are shown in Fig. 11. First of all it should be noted that the results obtained with analytical-numerical method correspond to local buckling, so for easier comparison the curve denoted by "FEM local" was obtained for beam with length $L=L_{c r}=52 \mathrm{~mm}$ (see Tab.1). The beam deflection corresponding to local and global buckling mode and obtained for dimensionless load $\mathrm{M} / \mathrm{M}_{\mathrm{cr}}=2.4$ are presented in Fig. 12.

As it is presented in Fig. 13 the postbuckling equilibrium paths depend not only on the length of the beam but also depend on the chosen point in which the displacement for increasing load are collected. The curve denoted by number from 1 to 3 correspond to point presented in Fig. 12 in which the displacements are measured.

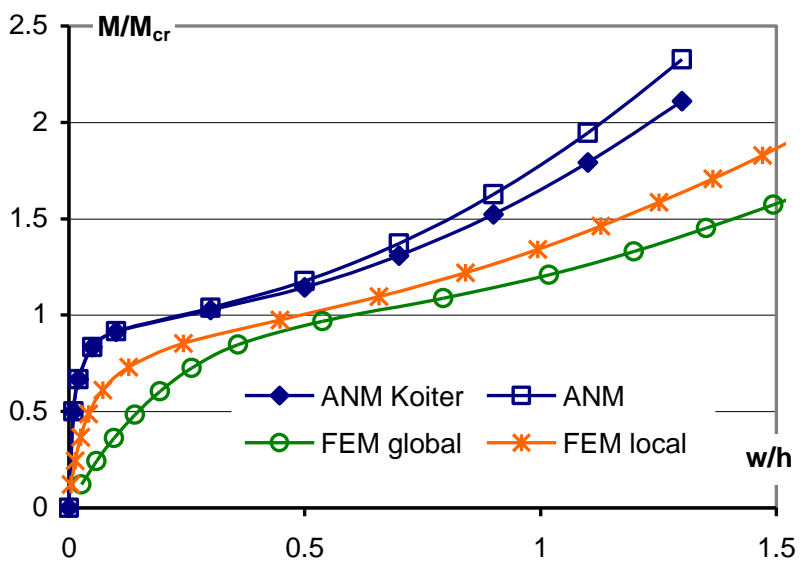

Fig. 11. Postbuckling equilibrium paths for channel section beam with ply arrangement $\mathrm{C} 2$ obtained with ANM and FEM a)

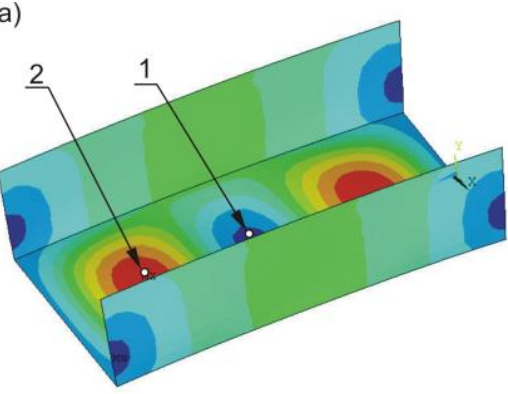

b)

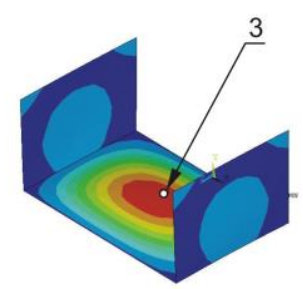

Fig. 12. Deflection obtained with FEM for beam of length $L=150 \mathrm{~mm}$ corresponding to global mode (a) and for beam with $L=52 \mathrm{~mm}$ corresponding local mode (b)

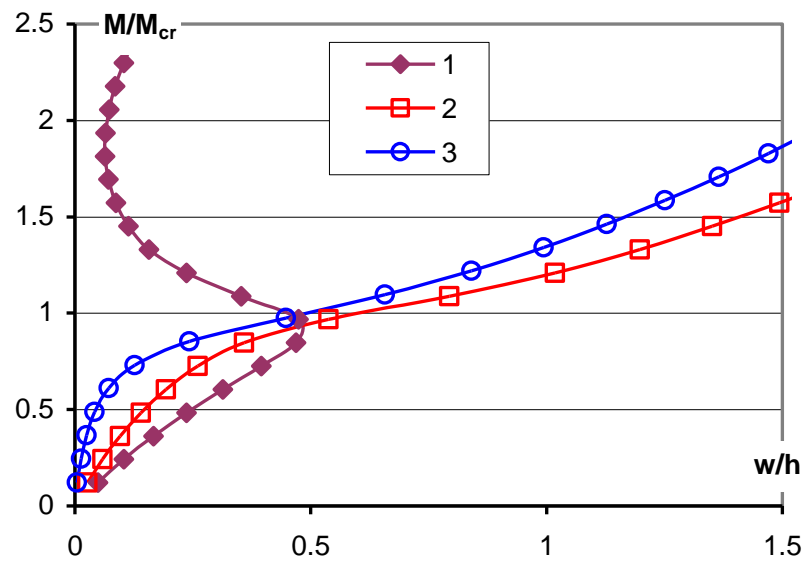

Fig. 13. Comparison postbuckling equilibrium paths for channel section beam with ply arrangement $\mathrm{C} 2$ obtained with FEM

Observing the coarse of the postbuckling equilibrium paths, especially the curve denoted by 1 (Fig. 13) it can be said that considered beam are bended - edge does not remain straight. Displacement of point 1 (Fig. 12) are in opposite direction than the edge of the channel section. When the displacement measured on the middle of the web (point 1 in Fig 12a) starts grows the collected displacement decrease for increasing load (curve 1 - Fig. 13) it happens for load corresponding to buckling load $\mathrm{M} / \mathrm{M}_{\mathrm{cr}}=0.9$ for channel section beam with geometrical imperfection. 


\section{CONCLUSIONS}

The results of calculation obtained using employed methods differ even about $20 \%$. Such a big differences shows that the experimental tests are necessary for numerical model validation.

The results show that the critical load for all analysed beams are similar, and their behaviour after the loss of stability depends strongly on the layers arrangement.

Differences in the results obtained with both employed methods depend on assumptions and because the prebuckling bending have not been taken into account in the analytical-numerical method.

The one of the aims of presented investigation was to choose the ply arrangement of produced channel sections samples which will be used in experimental tests.

The results of calculations for beams with seven different ply arrangements shows, that is enough to choose only three of them for which the postbuckling equilibrium paths differ in the most.

\section{REFERENCES}

1. Ambartsumyan S.A. (1970), Theory of anisotropic plates, Technomic.

2. Ashton J.E., Whitney J.M. (1970), Theory of Laminated plates, Technomic

3. Bernoulli J., Euler L. (1910), Abhandlungen uber das Gleichegewicht und die Schwingungen der Ebenen Elastischen Kurven, Wilhelm Engelmann, 175, Leipzig.

4. Brunelle E.J., Oyibo G.A. (1983), Generic buckling curves for specially orthotropic rectangular plates, AIAA 21, 8, 1150-115.

5. Byskov E., Hutchinson J. W. (1977), Mode interaction in axially stiffened cylindrical shells, AIAA 15(7), 941-948

6. Chailleux A., Hans Y., Verchery G. (1975), Experimental study of the buckling of laminated composite columns and plates, Int. J. Mechanical Science 17, 489-498.

7. Chandra R., Raju B. (1973), Postbuckling analysis for rectangular orthotropic plates, Int. J of Mechanical Science 16, 81-97.

8. Debsski H., Kubiak T., Teter A. (2013), Buckling and postbuckling behaviour of thin-walled composite channel section column, Composite Structures 100, 195-204

9. Fraser Jr., H.R., Miller R.E. (1970), Bifurcation type of buckling of generally orthotropic clamped plates, AIAA 8, 4, 707-712.

10. Gupta R.K., Rao K.P. (1985), Instability of laminated composite thinwalled open-section beams, Composite Materials 4, 299-313.

11. Koiter W.T. (1976), General theory of mode interaction in stiffened plate and shell structures, WTHD, Report 590, Delf.
12. Kołakowski Z., Kowal-Michalska K. (eds), (1999), Selected problems of instabilities in composite structures A series of monographes, Technical University of Lodz Press.

13. Kolakowski Z., Kubiak T. (2005), Load-carrying capacity of thinwalled composite structures, Composite Structures 67, 417-426.

14. Kolakowski Z., Kowal-Michalska K. (eds), (2012), Static, dynamic and stability of structures, Vol. 2, Statics, dynamics and stability of structural elements and systems, A series of monographs, Technical University of Lodz Press, Lodz.

15. Kolakowski Z., Mania R.J. (2013), Semi analytical method versus the FEM for analysis of the local post-buckling of thin-walled composite structure, Composite Structures 97, 99-106.

16. Kubiak T. (2001), Postbuckling behavior of thin-walled girders with orthotropy varying widthwise, Int. J. Solid and Structures 38, 28-29, 4839-4856.

17. Lekhnitskii S. (1947), Anisotropnyje plastinki, Moscow-Leningrad.

18. Libove C., (1983), Buckle pattern of biaxially compressed simply supported orthotropic plates, Jnt. of Comp. Materials 17, 45-48.

19. Mandell J.M. (1968), An experimental study of the postbuckling of anisotropic plates, M.S. thesis, Case Western Reserve University.

20. March H. (1942), Buckling of flat plywood plates in compression, shear or combined compression and shear, Forest Products Laboratory, Rep. 1316.

21. Massey C. (1971), The elastic buckling of orthotropic rectangular plates, Civ. Eng. Trans. CE13, 1, 63-65.

22. Noor A.K. (1975), Stability of multilayered composite plates, Fibre Science and Technology 8, 81-89.

23. Prahakara M.K. Chia C.Y. (1973), Postbuckling behaviour of rectangular orthotropic plates, Jnl. Mech. Eng. Sci. 17, 25-33.

24. Reissner. E., Stavsky. Y. (1961), Bending and stretching of certain types of heterogeneous aelotropic elastic plates, Trans ASME Jnl. of Appl. Mech. 9, 402-408.

25. Seydel E. (1933), The critical shear load of rectangular plate, NACA TM 705.

26. Smith R.C.T. (1944), The buckling of flat plywood plate in compression, Australian Council for Aeonautics Rep. 12.

27. Thielemann W. (1950), Contributions to the problem of buckling of orthotropic plates with special reference to plywood, NACA TM 1263.

28. Timoshenko S.P., Gere J.M. (1961), Theory of elastic stability, McGraw-Hill.

29. Ting T.K. Surdenans J. (1987), Buckling of rectangular orthotropic plates under biaxial loading, Jnl of Comp. Materials, 21, 124-128.

30. Vinson J.R. Chou T.W. (1975), Composite Materials and their use in structures, Applied Science Publisher Ltd.

31. Volmir S.A. (1967), Stability of Deformation Systems, Science, Moscow /in Russian/.

The paper has been written under research project financed by the National Centre for Science - decision No DEC-2011/03/B/ST8/06447. 